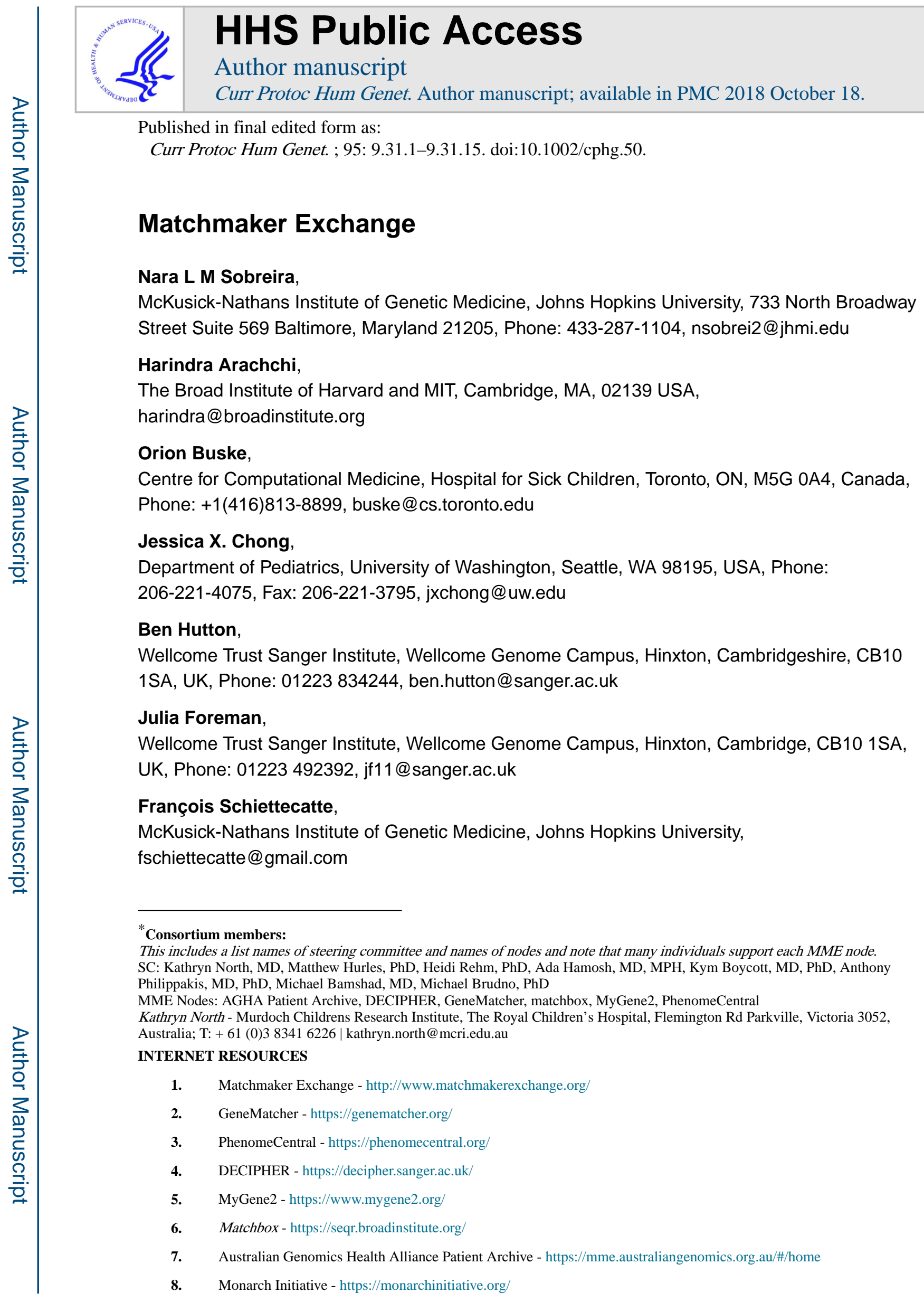




\section{Tudor Groza,}

Kinghorn Centre for Clinical Genomics, Garvan Institute of Medical Research, The Kinghorn Cancer Centre, Level 6, 370 Victoria Street, Darlinghurst, NSW 2010, Australia; St Vincent's Clinical School, Faculty of Medicine, University of New South Wales, Australia, Phone: $+61(0) 2$ 9355 5717, t.groza@garvan.org.au

\section{Julius O.B. Jacobsen,}

William Harvey Research Institute, Barts and The London School of Medicine and Dentistry, Queen Mary University of London, Charterhouse Square, London, EC1M 6BQ, UK, j.jacobsen@qmul.ac.uk

\section{Melissa Haendel,}

Director of the Ontology Development Group, Associate Professor, OHSU Library, Department of Medical Informatics \& Clinical Epidemiology, Phone: 503-407-5970, haendel@ohsu.edu

\section{Kym M Boycott,} Children's Hospital of Eastern Ontario Research Institute, University of Ottawa, 401 Smyth Rd, Ottawa, Ontario, K0A 2P0, Canada, Phone:1-613-737-7600 (4139), kboycott@cheo.on.ca

Ada Hamosh, and

Dr. Frank V. Sutland Professor, McKusick-Nathans Institute of Genetic Medicine (IGM), Clinical Director, IGM. Scientific Director, OMIM. Johns Hopkins University. Blalock 1007600 N. Wolfe St Baltimore, MD 21287-4922, Phone: 410-614-3313, Fax: 410-614-9246, ahamosh@jhmi.edu

\section{Heidi L. Rehm* on behalf of the Matchmaker Exchange Consortium}

The Broad Institute of Harvard and MIT, Cambridge, MA, 02139 USA, Phone: 617-768-8291, hrehm@broadinstitute.org

\section{Abstract}

In well over half of the individuals with rare disease who undergo clinical or research nextgeneration sequencing, the responsible gene cannot be determined. Some reasons for this relatively low yield include unappreciated phenotypic heterogeneity; locus heterogeneity; somatic and germline mosaicism; variants of uncertain functional significance; technically inaccessible areas of the genome, incorrect mode of inheritance investigated; and, inadequate communication between clinicians and basic scientists with knowledge of particular genes, proteins or biological systems. To facilitate such communication and improve the search for patients or model organisms with similar phenotypes and variants in specific candidate genes we have developed the Matchmaker Exchange (MME). MME was created to establish a federated network connecting databases of genomic and phenotypic data using a common application programming interface (API). To date, seven databases can exchange data using the API (GeneMatcher, PhenomeCentral, DECIPHER, MyGene2, matchbox, Australian Genomics Health Alliance Patient Archive, and Monarch Initiative), the later included for model organism matching. This protocol guides usage of the MME for rare disease gene discovery.

\section{Keywords}

Matchmaker Exchange; candidate genes; GeneMatcher; PhenomeCentral; DECIPHER; MyGene2; matchbox; Australian Genomics Health Alliance Patient Archive; Monarch Initiative 


\section{INTRODUCTION}

In the last decade improvements in DNA sequencing technology have led to the use of nextgeneration sequencing (NGS) methods in many areas of science, including discovery research and clinical testing. Moreover, the use of exome sequencing (ES) has allowed the discovery of more than a thousand disease genes associated with rare Mendelian disorders (Chong et al., 2015; Boycott et al, 2017). Despite these advances, in more than half of the individuals with a rare Mendelian phenotype who undergo clinical or research ES, the responsible gene cannot be identified (Yang et al., 2014; Chong et al., 2015; Retterer et al., 2015). Some of these cases harbor variants in one or more novel candidate genes and the necessary evidence for causally implicating the disease gene often comes down to identifying other affected individuals with similar phenotype and functionally impactful variants in the same candidate gene. Many databases have addressed this need by developing platforms that use genomic and phenotypic matching algorithms to identify cases with similar phenotypes and variants in the same gene (Washington et al., 2009; Gonzalez et al., 2012, Swaminathan et al., 2012, Gonzalez et al., 2013, Robinson et al., 2014; Zemojtel et al., 2014; Buske et al., 2015a; Lancaster et al., 2015; Sobreira et al., 2015a). MME was created to establish a federated network connecting these databases of genomic and phenotypic data using a common application programming interface (API) and allowing data exchange among them. Here we provide two protocols including 1. Using an existing matchmaker exchange database to search for a match, and 2. Connecting a database to the MME. In the commentary section we describe the consent requirements for MME and how patients can use the MME.

\section{BASIC PROTOCOL 1}

\section{USING AN EXISTING MATCHMAKER DATABASE TO SEARCH FOR A MATCH}

The main MME Web site is accessible via the Internet at (http:// www.matchmakerexchange.org/) (Figure 1). Its home page contains information on how to get started with matchmaking, available resources needed to support matchmaking, who the participants are and how to contact us (Figure 1). It also contains an overview of MME (Figure 2). In the HOW TO GET STARTED tab in the home page users can identify themselves as an individual with a case to match, an individual with a dataset to deposit or an individual with a database to connect to the MME.

To date, seven databases can Exchange data using the API: GeneMatcher (https:// genematcher.org/), PhenomeCentral (https://phenomecentral.org/), DECIPHER (https:// decipher.sanger.ac.uk/), MyGene2 (https://www.mygene2.org/), matchbox (https:// seqr.broadinstitute.org/), Australian Genomics Health Alliance Patient Archive (https:// mme.australiangenomics.org.au/\#/home), and Monarch Initiative (https:// monarchinitiative.org/) (Figure 2). To initiate a search the users should first identify themselves as clinicians, laboratories or patients (Figure 3). In the HOW TO GET STARTED tab in the home page users identified as clinicians or laboratories can find a page with detailed description of each database connected to MME including: 1 - The database location and types of data stored by each database (Figure 4); 2 - Parameters used for 
matching and score output (Figure 5); 3 - MME connections (Figure 6); 4 - Types of users (Figure 7); and 5 - MME matching and notification protocols. After the review of this information the user can choose what database to use as their primary point of entry into the MME, which is where they will deposit their data and initiate queries of the other databases. The queries allow a gene symbol with or without a specific variant and/or variant attributes (e.g. de novo, loss of function, etc.) a disease name or phenotypic features, to be sent as a query to get a match notification about any similar cases. Matching algorithms are defined by the matchmaker services and have evolved over time.

Necessary Resources-The minimal resources required for matchmaking is an internet connected device and a gene candidate symbol, a set of Human Phenotype Ontology (HPO) terms to describe the patient's phenotype, or both.

\section{From GeneMatcher to other MME databases}

1. Create a GeneMatcher account at https://genematcher.org/.

2. Create a submission at "Create a new submission" in the home page (Figure 8).

3. Evaluate the options and check the relevant boxes before fitting the "Save Submission" button (Figure 9):

a. Choose what other MME databases to query (Figure 9).

b. Choose what data to send to the other MME databases (Figure 9).

c. If desired, choose to automatically send the data from this submission to other MME databases monthly (Figure 9).

4. Fill out the Submission Identification information, including your name, institution, and email address, as well as a unique identifier to tag this entry.

Users will be notified of all matches via email and matches are also displayed at the Match Report tab (Figure 10).

5. In the Match Report page, record the outcome of the match follow up as shown in Figure 11.

\section{From PhenomeCentral (PC) to other MME databases}

1. Create a PhenomeCentral account at https://phenomecentral.org/

2. Create a patient at "Create... New Patient" in the homepage.

3. Grant consent to sharing the patient over the MME by checking the corresponding box and saving the patient record (Figure 12); this allows the patient to be matched against by other databases.

4. Queries are initiated in several ways:

4a Users can initiate queries and view matches by going to a patient record, scrolling to the "Matches in partner MME databases" section, and clicking "Find matches" next to the desired database (or "Refresh matches" to send a new request) (Figure 13). 
4b Queries are periodically re-sent for all patients to all connected databases, and a genetic counsellor reviews the quality of the matches and decides whether to send a notification email to the PhenomeCentral user.

\section{From DECIPHER to other MME databases}

1. Create a DECIPHER account at https://decipher.sanger.ac.uk.

Membership of DECIPHER is open to academic centers of clinical genetics and research institutions that intend to deposit and share consented patient data. Users can either join an established project or apply for a new project; criteria for joining DECIPHER can be viewed here: https://decipher.sanger.ac.uk/join\#info.

2. Create a submission by creating a patient record and adding genotype and phenotype information. To patient match via MME, the patient record must be marked as consented for open sharing (requires patient consent) and must include at least one open-access sequence variant.

3. In the patient record, click on the "Matchmaker" tab and then click on the "Query Matchmaker Exchange" button (Figure 14).

4. By clicking on "Query Matchmaker Exchange", connected databases will be queried for patient records that share similarity with the linked anonymous consented patient record, and the results will be displayed on the Matchmaker tab in the patient record.

\section{From MyGene2 to other MME databases}

1. Create a clinician or researcher MyGene2 account at https://www.mygene2.org

2. Create a submission at "Create new case."

3. If the case created is not classified as a known gene for a known phenotype, the data will be automatically submitted to other MME databases.

4. The users will be notified of all matches via email and matches are also summarized via the Matchmaker Exchange Dashboard (Figure 15).

\section{From matchbox to other MME databases}

1. The use of matchbox at the Broad Institute is currently only supported for users storing their rare disease genomic data in seqr (https://seqr.broadinstitute.org/) at the Broad Institute (Figure 16). To collaborate with the Broad Center for Mendelian Genomics and use seqr and matchbox software tools, contact cmgbroadinstitute.org.

\section{From Australian Genomics Health Alliance Patient Archive to other MME databases}

1. Create an account with the AGHA Patient Archive at https://

mme.australiangenomics.org.au/ 
2. Create a new patient at the dashboard.

3. Add the phenotype and genotype profile of the proband.

4. Share the patient with the MME; users have the choice of sharing phenotypes, genes and diagnoses (Figure 17), as well as to opt in or out for being notified on external matches.

5. Once the patient has been shared, the user can query the other MME databases; all databases will be queried at once.

6. Results will be displayed on demand (Figure 18).

7. Subject to the notification setting chosen when sharing the patient, the users will be notified by email when external matches occur.

From Monarch Initiative to other MME databases-The Monarch Initiative does not send queries to the other MME databases. It receives queries and returns genotype and HPO phenotype based-matches with known human diseases (e.g. ClinVar, Orphanet, etc) and animal models to assist in evidence gathering.

\section{BASIC PROTOCOL 2}

\section{CONNECTING A DATABASE TO MATCHMAKER EXCHANGE}

If the user has a database to connect to the MME he/she will find the requirements and the contact email (apimatchmakerexchange.org) by clicking at "I have a database to connect" (Figure 3).

This protocol will walk you through the main steps to connect an existing genomic and/or phenotypic database to MME allowing the exchange of data with the other MME databases.

Necessary Resources-The only resource required is an internet-connected computer.

Application programming interface (API)—The databases of the MME communicate with each other using a common API that exchanges data in JSON. This API is documented and maintained collaboratively at the MME GitHub repository (https://github.com/ga4gh/ mme-apis) by the technical working group.

For a new database to join the MME, there are two main technical steps that must be undertaken:

1. The database must first implement the MME API. At a high level, connecting a database to the MME involves exposing an API endpoint "/match" that allows another MME database to query your database for similar patients. The queried database replies with a list of other similar patients that it hosts. The algorithm that decides similarity is defined by the database being queried. A database can either develop the necessary software to implement the API themselves or use one of the existing open-source implementations that simplify the process of connecting a database to the MME. There are currently two portable, open- 
source solutions available: the MME reference server (https://github.com/ MatchmakerExchange/reference-server) and the matchbox system (https:// github.com/macarthur-lab/matchbox). Other open-source implementations of the MME API can be found here: https://github.com/ga4gh/mme-apis/wiki/ Implementations.

2. Once the API is implemented, the database must exchange some basic information with the other databases it wants to connect to. MME is a peer-topeer federated network, where each database connects to two or more other databases within the network. Because of the sensitivity of the information being shared, most MME databases require requests from other databases to be authenticated with a pre-shared key (PSK). These keys are usually shared via encrypted email messages. This process of connecting to other databases can be time consuming, but it assures each database full control over who it shares data with.

\section{COMMENTARY}

\section{Background Information}

The main evidence to identify novel disease genes associated with rare Mendelian phenotypes is the identification of other affected individuals with similar phenotype and variants in the candidate genes. Historically, clinicians and researches have been identifying these additional cases by personal communication, presentation of abstracts in scientific meetings, publication of case reports, etc. More recently, the rapid development of informatics tools has made this process faster and more efficient. Projects such GeneMatcher, PhenomeCentral, DECIPHER, MyGene2, matchbox, Australian Genomics Health Alliance Patient Archive, Monarch Initiative and others have allowed the discovery of many novel disease genes by connecting clinicians, researchers and patients from all around the world.

MME was created in October 2013 to facilitate the connection among these databases allowing the users to store their data in one database and query the others without the need to create multiple accounts and store the same data in more than one database.

Value of federation-A federated model was chosen to support the MME. The federated architecture provides several benefits to other, more centralized approaches such as:

1. Data locality - each database hosts, maintains ownership and is responsible for the safekeeping of their own data. It also enables them to comply with any national or regional restrictions on data storage and sharing;

2. Data privacy - data security and privacy management are not entirely in the hands of one, centralized database. Each database has full control over which other databases it wishes to connect to, and what information is exchanged with each of these other databases; 
3. Network robustness - because there is no central server, there is no single point of failure for the MME; if one database goes offline, all connections between other databases will be unaffected;

4. Algorithm development and data maintenance - each database has full autonomy to develop and evolve their matching algorithms independently. A federated system also makes it easier to support updates to patient phenotype and updated genomic interpretations over time.

The federated approach allows each MME database to maintain its autonomy and primary purpose, while contributing valuable data to the MME and the genomics community. Users no longer need to submit the same datasets into multiple databases to find matches, and they will have more options for databases in which to store data, including databases in their own jurisdiction if certain regulations prohibit data from leaving a region. Also, users may decide to put some cases into one database and other cases into another database depending on the focus (clinical and/or data types) of each database (Philippakis et al., 2015).

Consent requirements-The MME consent policy (Informed Consent Policy) can be found at the web page under OUR RESOURCE LIBRARY (Figure 3). This approach was developed in collaboration with the Global Alliance for Genomics and Health (GA4GH) Regulatory and Ethics Working Group (REWG) members and their Consent Task Team and is detailed in Dyke et al 2017.

The approach has two levels depending on the type of data being deposited in the system as well as two data types (clinical vs research). This allows patient consent needs to be defined based on the probability of occurrence and seriousness of potential harm of re-identification in the matchmaking process as well as the expectations of the patient/study subject. For level 1 , when only a candidate gene $+/-$ non-sensitive structured phenotype data are provided, written patient consent is not required if matching is submitted in support of clinical care (e.g. a diagnostic clinical exome report with a reported novel candidate gene) given that matching efforts are consistent with clinical care but may be required for research subjects. For level 2, when variant-level data and/or sensitive phenotypic data is provided, written consent is typically required because the likelihood of re-identification and/or the potential for harm is higher.

Patient use of MME-Although all matchmaker services support the entry of patient data by clinicians and researchers, two MME databases support direct use of their databases by patients and their families. These include GeneMatcher and MyGene2, both of which currently support patient-led matching within their databases (though now not yet across the MME platform) to help identify other individuals with similar profiles. Patients or family members should be aware that a health care provider (including the clinical laboratory that performed the test) may have already created a submission with the same novel disease gene candidate which could result in a match based on the same patient within a given database.

As of today, the other MME databases do not yet accept queries directly from patients. Patients or family members wishing to query all MME databases should contact their 
healthcare provider who ordered their testing, to create a submission to allow query across the entire MME platform.

\section{Critical Parameters}

Optimizing for success in matchmaking-To enable the most successful matches and facilitate efficient follow-up communication after match notifications have been sent by email, users are encouraged to submit detailed phenotypic and suspected inheritance information at the initial point of entry of their candidate gene, as well as restrict genes to highly likely candidates. For example, usually only a single or small number of candidate genes are submitted per patient/research subject such as those candidate genes in which a variant arose de novo or has biallelic variants absent from (or extremely rare in) general population databases or has some functional evidence supporting the gene's potential role in disease.

By providing phenotypic data during submission, matches will be ranked with higher scores based on matching algorithms that incorporate phenotype. And finally, a data depositor may be more likely to respond to a match notification email if they can immediately see a phenotypic and inheritance match provided in the notification email.

\section{Troubleshooting}

If troubleshooting on how to connect a database to MME, the user should contact us at api@matchmakerexchange.org.

If troubleshooting on how to find a match in the MME databases, the user should contact the database where the data are primarily stored.

\section{Anticipated Results}

After the submission of a query to one or more of the MME databases the users will receive an email informing them of the presence or absence of a match in the queried database(s).

If there is currently no match in any of the databases, the user will be notified and the submission will only be stored in the database from which the query originated, not the external databases queried. In the future, if the users would like to repeat the query they would need to send the submission again. In several databases, the users have the option to automatically resend the data from their submissions to the MME on a periodic basis.

If there is an instant match, all data depositors involved in the match will be notified according to notification procedures maintained by each database and described in detail here: http://www.matchmakerexchange.org/assets/files/ MME_Matching_Protocols_and_Notification_Method_2017-04-03.pdf

The email about the match typically includes the information that matched and the email contact of the users involved. Sometimes a score is included to define the strength of a match or the relevant rank if multiple cases match. The users contact each other to exchange additional detailed information about the gene, variant, mode of inheritance, phenotype, etc. 


\section{Time Considerations}

When a MME match occurs, the submitters will automatically and immediately (in few seconds/minutes) receive an email notification.

\section{Acknowledgments}

The authors acknowledge the contributions of the entire MME as well as GA4GH, IRDiRC and the Centers for Mendelian Genomics and Care4Rare Canada in advancing this collaborative initiative.

Contract grant sponsors: NIH (grants 1U54HG006542, UM1HG008900, 5R24OD011883, U54HG006493), Genome Canada (CAN-SHARE)

\section{LITERATURE CITED}

Boycott KM, Rath A, Chong JX, Hartley T, Alkuraya FS, Baynam G, Brookes AJ, Brudno M, Carracedo A, den Dunnen JT, Dyke SOM, Estivill X, Goldblatt J, Gonthier C, Groft SC, Gut I, Hamosh A, Hieter P, Höhn S, Hurles ME, Kaufmann P, Knoppers BM, Krischer JP, Macek M Jr, Matthijs G, Olry A, Parker S, Paschall J, Philippakis AA, Rehm HL, Robinson PN, Sham PC, Stefanov R, Taruscio D, Unni D, Vanstone MR, Zhang F, Brunner H, Bamshad MJ, Lochmüller H. International Cooperation to Enable the Diagnosis of All Rare Genetic Diseases. Am J Hum Genet. 2017 May 4; 100(5):695-705. [PubMed: 28475856]

Buske OJ, Girdea M, Dumitriu S, Gallinger B, Hartley T, Trang H, Misyura A, Friedman T, Beaulieu C, Bone WP, Links AE, Washington NL, et al. PhenomeCentral: a Portal for Phenotypic and Genotypic Matchmaking of Patients with Rare Genetic Diseases. Hum Mutat. 2015 Oct; 36(10): 931-40. [PubMed: 26251998]

Chong JX, Buckingham KJ, Jhangiani SN, Boehm C, Sobreira N, Smith JD, et al. The genetic basis of Mendelian phenotypes: discoveries, challenges, and opportunities. Am. J. Hum. Genet. 2015; 97:199-215. [PubMed: 26166479]

Gonzalez MA, Van Booven D, Hulme W, Ulloa RH, Lebrigio RF, Osterloh J, Logan M, Freeman M, Zuchner S. Whole Genome Sequencing and a New Bioinformatics Platform Allow for Rapid Gene Identification in D. melanogaster EMS Screens. Biology. 2012; 1(3):766-77. [PubMed: 24832518]

Gonzalez MA, Lebrigio RFA, Van Booven D, Ulloa RH, Powell E, Speziani F, Tekin M, Schule R, Zuchner S. GEnomes Management Application (GEM.app): A new software tool for large-scale collaborative genome analysis. Hum Mutat. 2013; 34(6):842-846. [PubMed: 23463597]

Lancaster O, Beck T, Atlan D, Swertz M, Dagleish R, Brookes AJ. Cafe Variome: general-purpose software for making genotype-phenotype data discoverable in restricted or open access contexts. Hum Mutat. 2015 Oct; 36(10):957-64. [PubMed: 26224250]

Philippakis AA, Azzariti DR, Beltran S, Brookes AJ, Brownstein CA, Brudno M, Brunner HG, Buske OJ, Carey K, Doll C, Dumitriu S, Dyke SO, den Dunnen JT, Firth HV, Gibbs RA, Girdea M, Gonzalez M, Haendel MA, Hamosh A, Holm IA, Huang L, Hurles ME, Hutton B, Krier JB, Misyura A, Mungall CJ, Paschall J, Paten B, Robinson PN, Schiettecatte F, Sobreira NL, Swaminathan GJ, Taschner PE, Terry SF, Washington NL, Züchner S, Boycott KM, Rehm HL. The Matchmaker Exchange: a platform for rare disease gene discovery. Hum Mutat. 2015 Oct; 36(10): 915-21. [PubMed: 26295439]

Retterer K, Juusola J, Cho MT, Vitazka P, Millan F, Gibellini F, et al. Clinical application of wholeexome sequencing across clinical indications. Genet. Med. 2015 Jul.18:696-704. [PubMed: 26633542]

Robinson PN, Köhler S, Oellrich A, Sanger Mouse Genetics Project. Wang K, Mungall CJ, Lewis SE, Washington N, Bauer S, Seelow D, Krawitz P, Gilissen C, et al. Improved exome prioritization of disease genes through cross-species phenotype comparison. Genome Res. 2014; 24(2):340-8. [PubMed: 24162188]

Sobreira N, Schiettecatte F, Boehm C, Valle D, Hamosh A. New Tools for Mendelian Disease Gene Identification: PhenoDB Variant Analysis Module; and GeneMatcher, a Web-Based Tool for 
Linking Investigators with an Interest in the Same Gene. Hum Mutat. 2015a; 36(4):425-31. [PubMed: 25684268]

Swaminathan GJ, Bragin E, Chatzimichali EA, Corpas M, Bevan AP, Wright CF, Carter NP, Hurles ME, Firth HV. DECIPHER: web-based, community resource for clinical interpretation of rare variants in developmental disorders. Hum Mol Genet. 2012; 21(R1):R37-R44. [PubMed: 22962312]

Washington NL, Haendel MA, Mungall CJ, Ashburner M, Westerfield M, Lewis SE. Linking human diseases to animal models using ontology-based phenotype annotation. PLoS Biol. 2009; 7(11):e1000247. [PubMed: 19956802]

Zemojtel T, Köhler S, Mackenroth L, Jäger M, Hecht J, Krawitz P, Graul-Neumann L, Doelken S, Ehmke N, Spielmann M, Oien NC, Schweiger MR, et al. Effective diagnosis of genetic disease by computational phenotype analysis of the disease-associated genome. Sci Transl Med. 2014; 6(252):252ra123.

Yang Y, Muzny DM, Xia F, Niu Z, Person R, Ding Y, et al. Molecular findings among patients referred for clinical whole-exome sequencing. JAMA. 2014; 312:1870-1879. [PubMed: 25326635] 


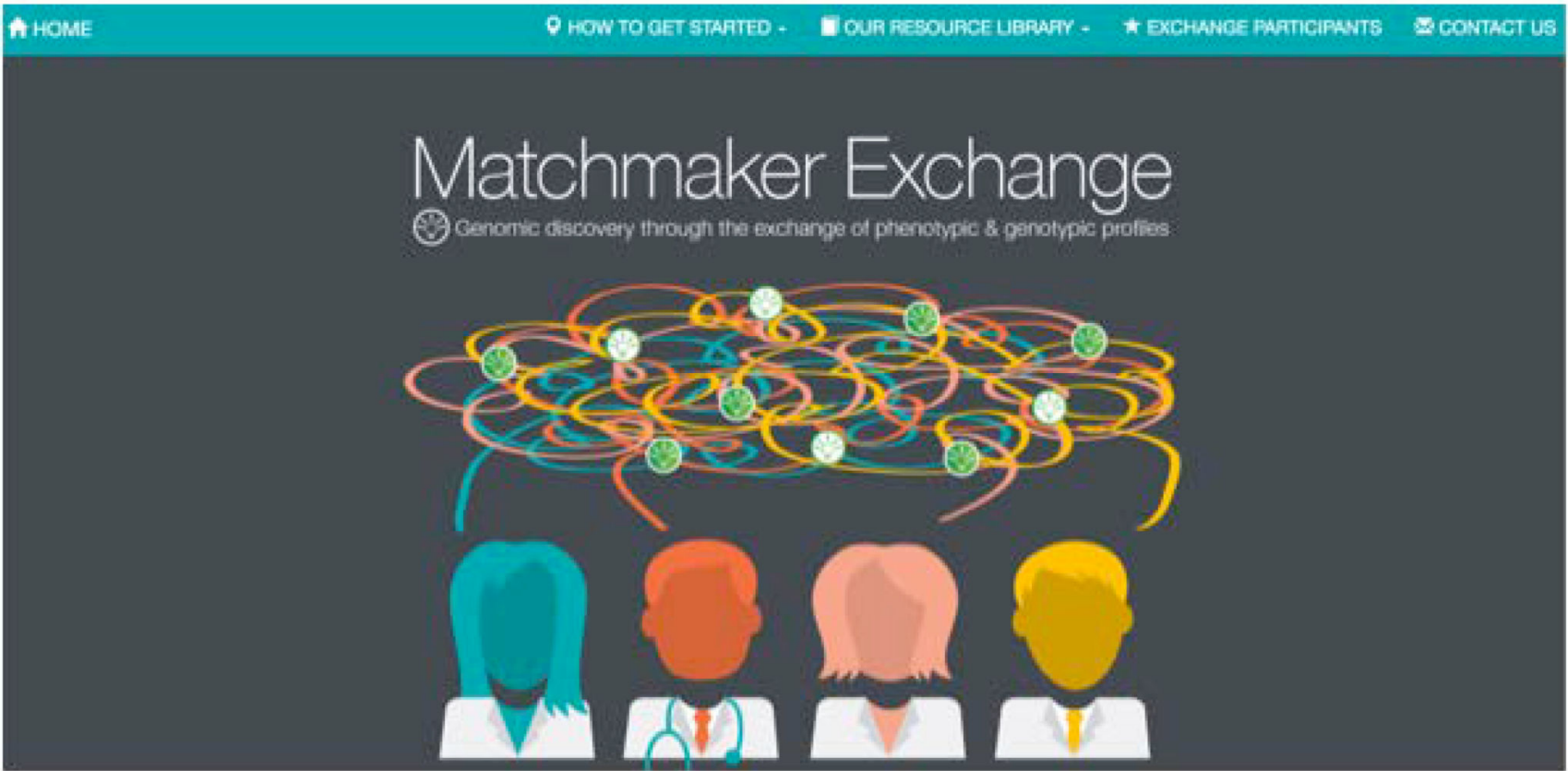

Figure 1.

Matchmaker Exchange Homepage. 
The Challenge

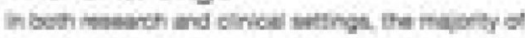

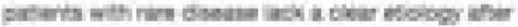

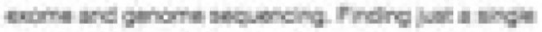

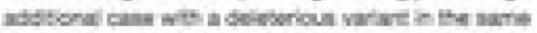

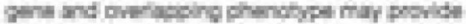

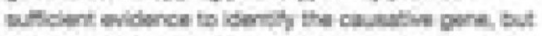

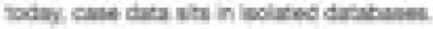

The Solution

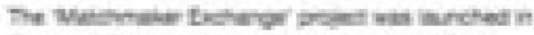

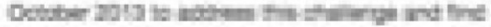

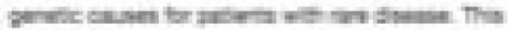

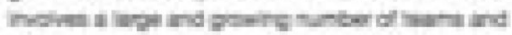

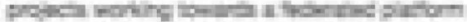

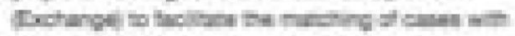

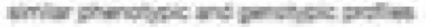

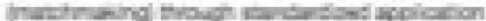

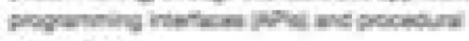
conterions

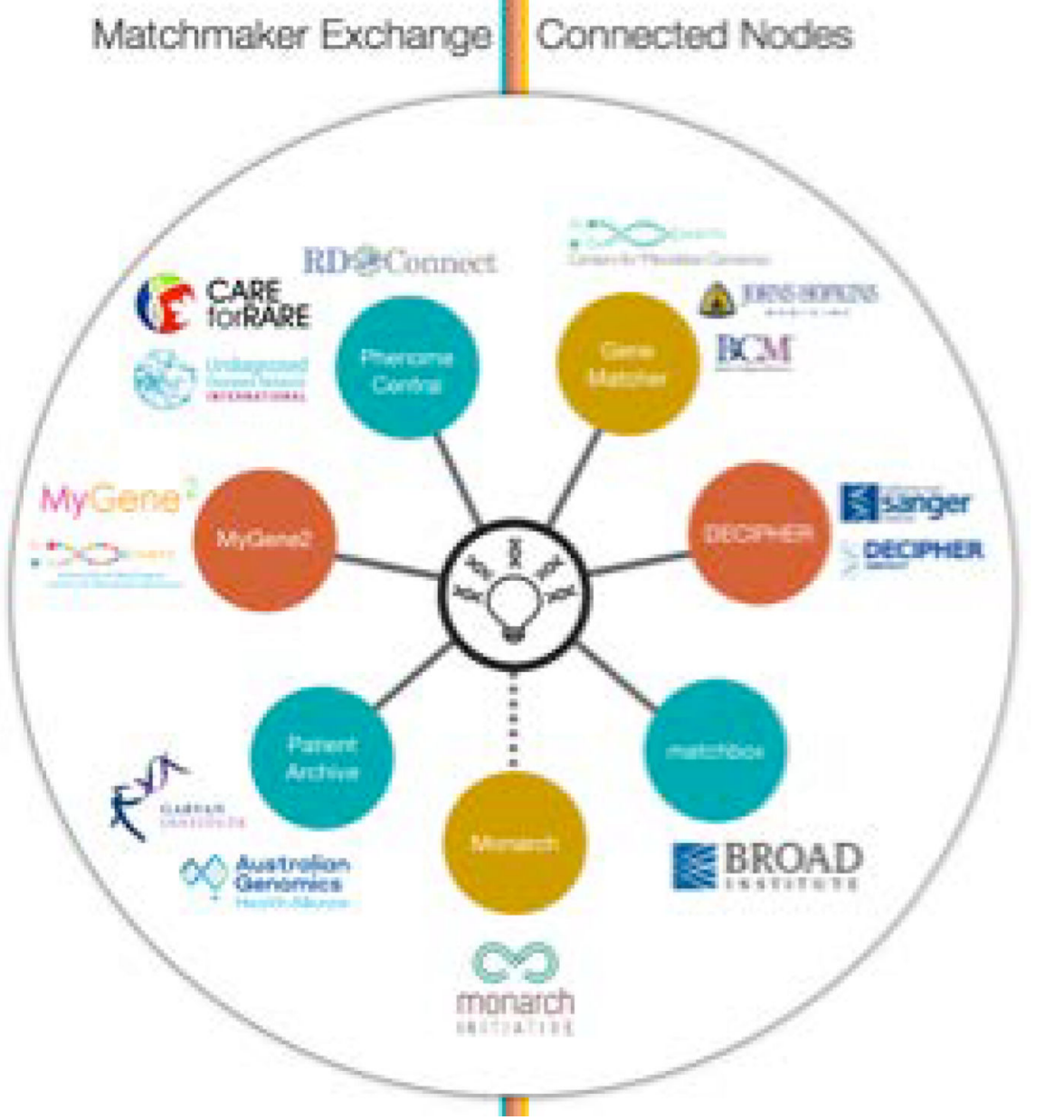

Figure 2.

Matchmaker exchange overview. 


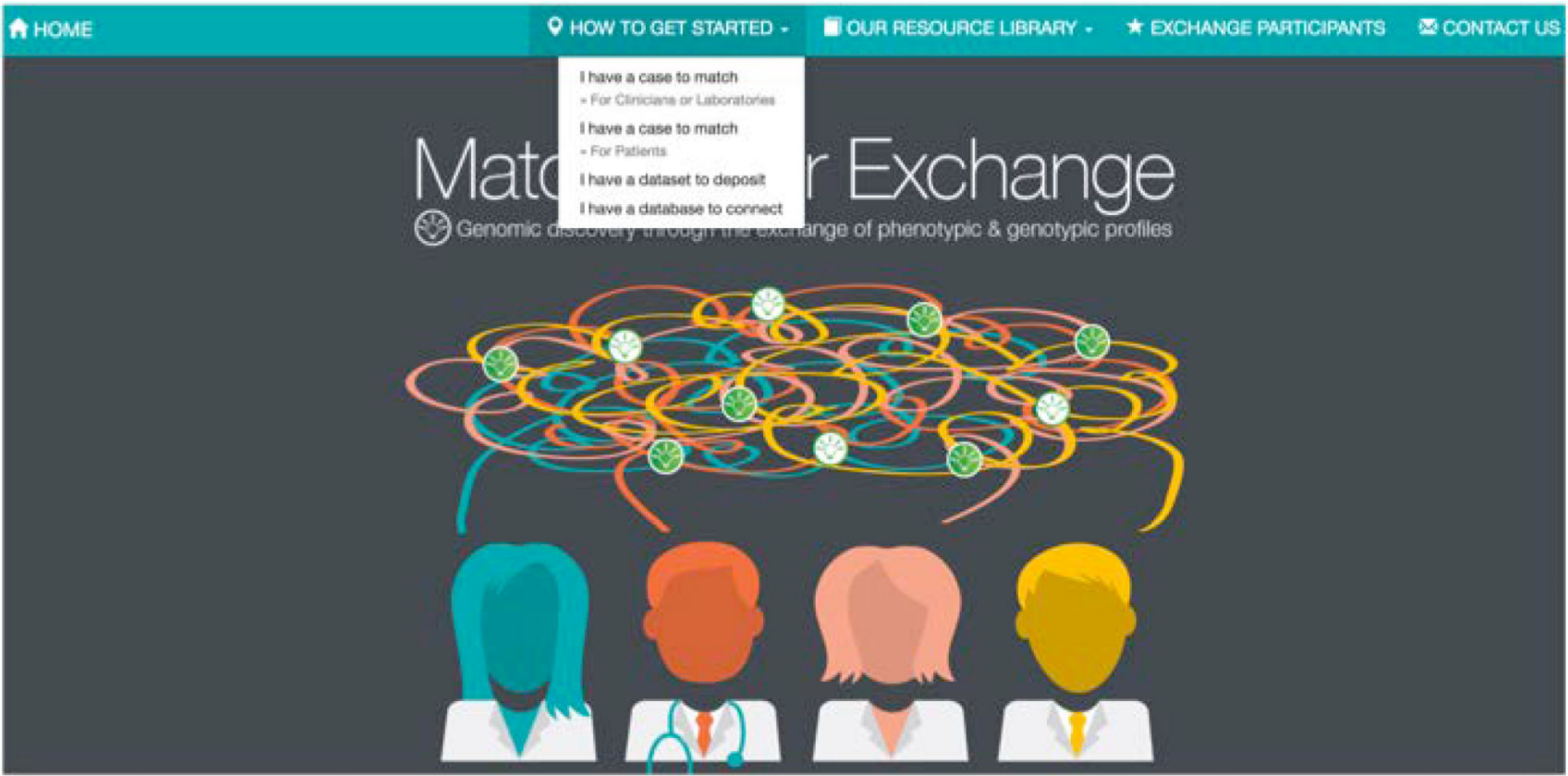

Figure 3.

How to get started. 
Types of Data Stored by Each of the Participating Matchmaker Exchange Services

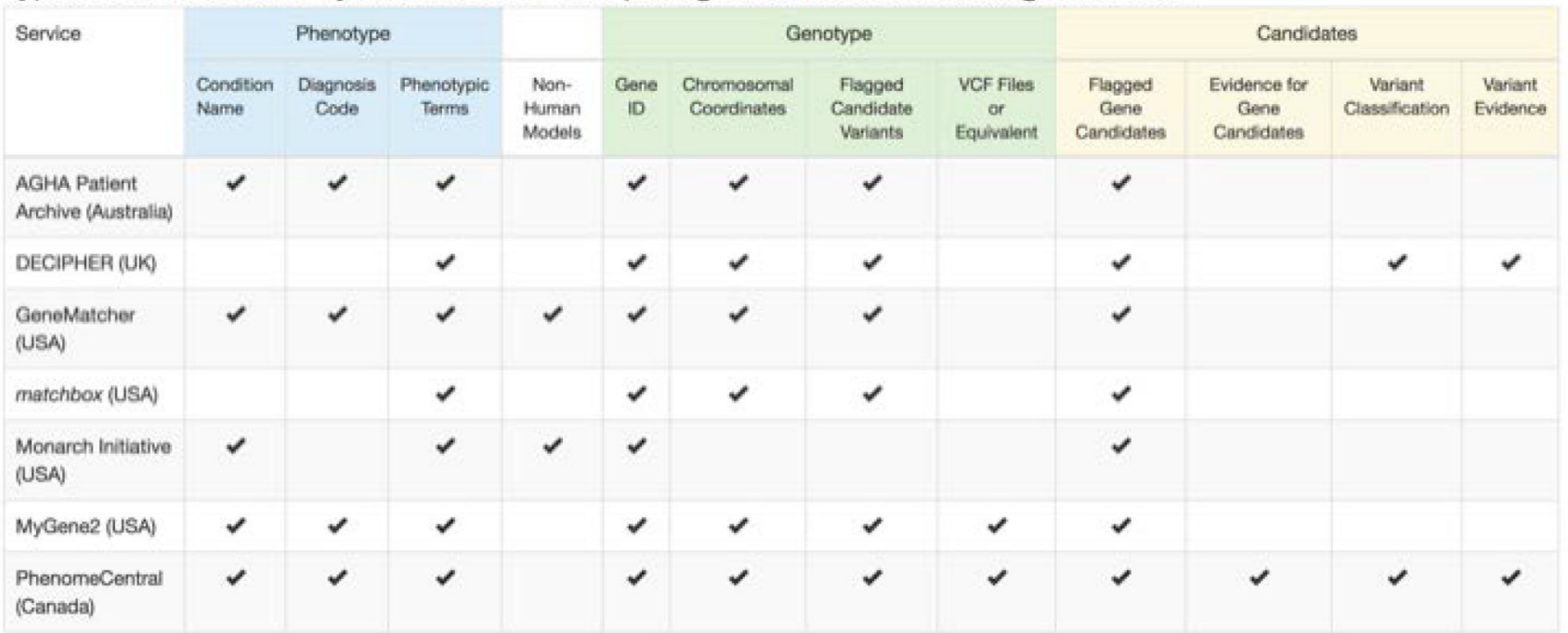

Figure 4.

Database location and types of data stored by each database. 


\begin{tabular}{|c|c|c|c|c|c|}
\hline Service & Gene ID & Diagnosis Code & $\begin{array}{l}\text { Phenotypic } \\
\text { Terms }\end{array}$ & $\begin{array}{c}\text { Variant } \\
\text { Parameters }\end{array}$ & $\begin{array}{l}\text { Provides Match } \\
\text { Score Output }\end{array}$ \\
\hline $\begin{array}{c}\text { AGHA Patient Archive } \\
\text { (Australia) }\end{array}$ & $v$ & & $v$ & & v \\
\hline DECIPHER (UK) & $\sqrt{ }$ & & v & $v$ & $\sqrt{ }$ \\
\hline GeneMatcher (USA) & $\sqrt{ }$ & V & $v$ & & $\sqrt{ }$ \\
\hline matchbox (USA) & $\sqrt{ }$ & & v & v & $\sqrt{ }$ \\
\hline Monarch Initiative (USA) & & & v & & $\sqrt{ }$ \\
\hline MyGene2 (USA) & $\sqrt{ }$ & & & & $\sqrt{ }$ \\
\hline $\begin{array}{l}\text { PhenomeCentral } \\
\text { (Canada) }\end{array}$ & v & v & $v$ & & $\mathrm{v}$ \\
\hline
\end{tabular}

Figure 5.

Parameters used for matching and score output. 


\begin{tabular}{|c|c|c|c|c|c|c|}
\hline \multirow[b]{2}{*}{ Responding Service } & \multicolumn{6}{|c|}{ Querying Service } \\
\hline & $\begin{array}{l}\text { AGHA Patient } \\
\text { Archive }\end{array}$ & DECIPHER & GeneMatcher & matchbox & MyGene2 & $\begin{array}{l}\text { Phenome } \\
\text { Central }\end{array}$ \\
\hline $\begin{array}{l}\text { AGHA Patient Archive } \\
\text { (Australia) }\end{array}$ & & & $v$ & v & $v$ & $v$ \\
\hline DECIPHER (UK) & & & $v$ & $\mathrm{v}$ & $v$ & $v$ \\
\hline GeneMatcher (USA) & $v$ & $v$ & & v & $v$ & $v$ \\
\hline matchbox (USA) & v & $v$ & $v$ & & $v$ & $\sqrt{ }$ \\
\hline Monarch Initative (USA) & v & & & & & $\sqrt{ }$ \\
\hline MyGene2 (USA) & v & $v$ & $v$ & v & & v \\
\hline PhenomeCentral (Canada) & $v$ & $v$ & $v$ & v & $v$ & \\
\hline
\end{tabular}

Figure 6.

Matchmaker exchange connections. 


\section{Types of Users}

\begin{tabular}{|l|l|l|}
\hline Service & $\checkmark$ \\
\hline AGHA Patient Archive (Australia) & $\checkmark$ \\
\hline DECIPHER (UK) & $\checkmark$ \\
\hline GeneMatcher (USA) & $\checkmark$ \\
\hline matchbox (USA) & $\checkmark$ \\
\hline Monarch Initiative (USA) & $\checkmark$ \\
\hline MyGene2 (USA) & $\checkmark$ \\
\hline PhenomeCentral (Canada) & $\checkmark$ \\
\hline
\end{tabular}

Figure 7.

Types of users allowed in each Matchmaker exchange database. 
A GeneMatcher Home - About Publications Statistics - Contact Us Help =

Matching Against Other Submissions

Match against other GeneMatcher submissions when this submission is saved

Match against Matchmaker Exchange repositories when this submission is saved

Save this Matchmaker Exchange match and rerun it every month

Matchmaker Exchange Repositories

Australian Genomics Health Alliance

Broad Matchbox

DECIPHER

MyGene2

PhenomeCentral

\section{Data Submitted}

MIM phenotype numbers

Gene symbols

Genomic locations

Features

You will be notified if there are new matches with other submissions in GeneMatcher, andjor you can run matches against other Matchmaker Exchange repositories.

9 Note that you need to select Gene symbols andjor Genomic locations andjor Features to submit to Matchmaker Exchange repositorles.

Save Submission

Curr Protoc Hum Genet. Author manuscript; available in PMC 2018 October 18. 


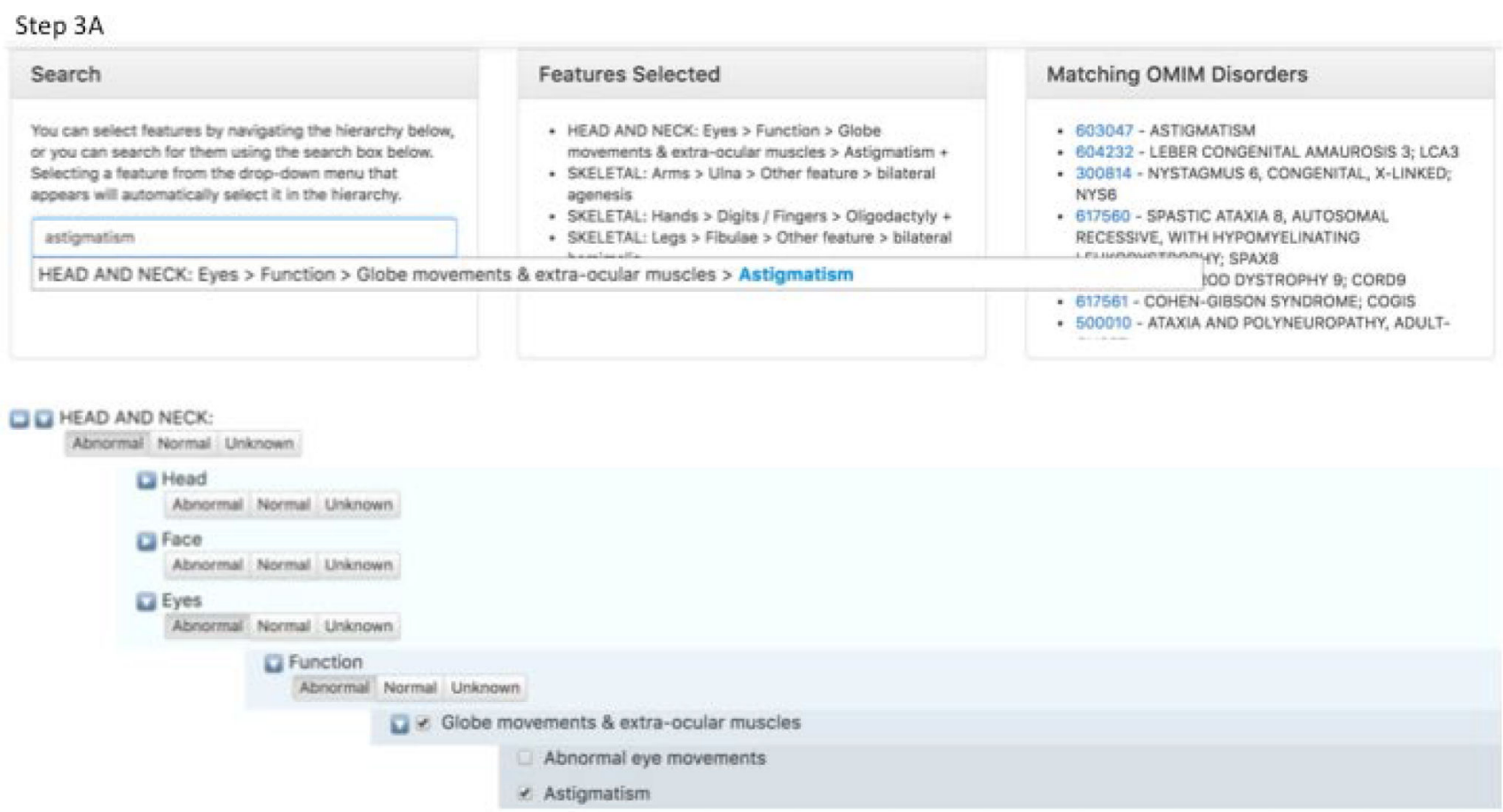

Figure 8.

How to create a general submission in GeneMatcher. Step 1 - Identify the organism being investigated. Step 2 - Classify the phenotype being investigated. Step 3 - Give pedigree information and add the features of the affected family members. Step 4 - Add gene name information, and variant information. Step 5 - Choose what data to match on.

Step 3A - By clicking at "Add features" the user is taken to a page were features can be added. 


\section{A GeneMatcher}

- Create a new submission

Step 1

Organism

Organlasm:

Human (Homo sapiens)

- You should only enier Human gene identliers in the Aesults section.

Step 2

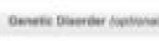

Dapminem

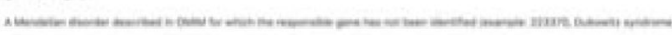

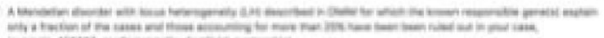

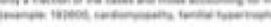

no

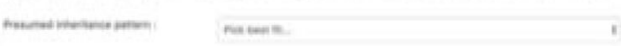

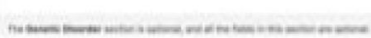

Step 3

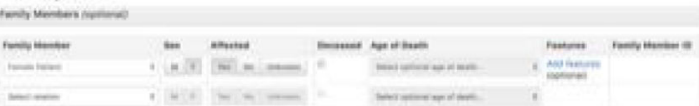

$-$

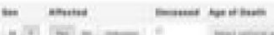

itisin-

Figure 9.

How to send data from GeneMatcher to other Matchmaker exchange databases.

Step 4

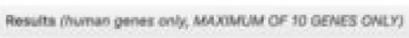

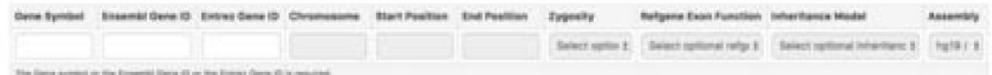

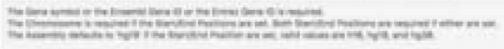

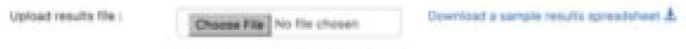

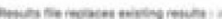

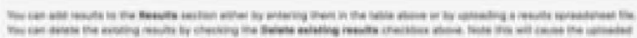

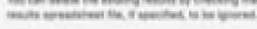

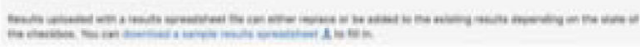

Step 5

Mutching Rules

ves phenowea number:

Gene symbal :

Oensmic location:

Fenures :

Festrikt matches is :

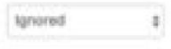

Fisoined a

genores

Geros :

D Anewriners

Ponticion Frowider

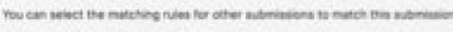

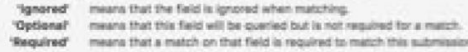

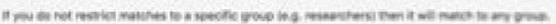


A GeneMatcher Home - About Publications Statistics - Contact Us Help *

View | Event Report | Match Report | Suspend $\boldsymbol{x}$ | Delete

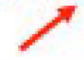

\section{Submission Identification}

Identifier :

Submitter email :

Submitter first name:

Submitter last name:

Submitter institution :
Required...

Optional, only needed if difforent from account email...

Optional only needed if different from account first name...

Optional, only needed if different from account last name...

Optional, only needed if different from account institution...

You need to provide an identifier that uniquely identifies this entry as it will be included in emails that are sent out when a match is made.

9 You should not use any information that could be used to identify the patient or their family.

$\boldsymbol{\theta}$ only enter the submitter email/name/institution if you are entering this data on behalf of someone else or if an additional person needs to be notified when a match occurs.

Figure 10.

In GeneMatcher, matches are displayed at the Match Report tab. 


\section{Match Event Outcome:}

\section{Select an outcome from one of the sections below:}

Awaiting outcome report

Phenotype mateh

Publication

Pubmed Io

Partial phenotype match

Not a phenotype match

Different inheritance mode

False positive variant

Variant didn't segregrate with phenotype

Commonly mutated gene

( multiple selections can be made in this section )

Same patient

Figure 11.

Recording the outcome of a match follow up in GeneMatcher. 


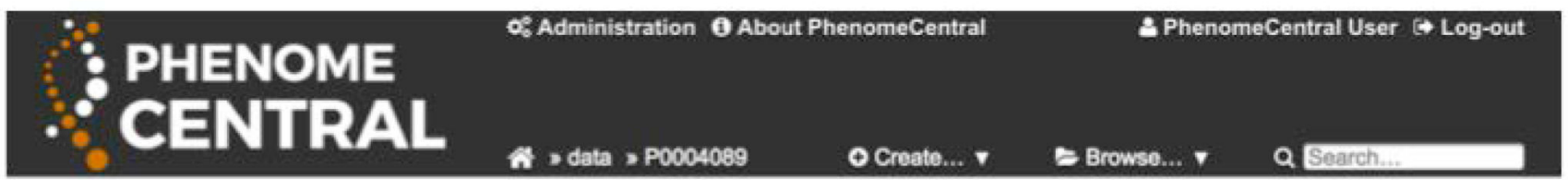

\section{P0004089 \\ Reported by PhenomeContral User on $2017 / 07 / 111622$}

Consents granted

2 I confirm that the data entered in this form corresponds to a real patient. (required)

01 confirm that consent has been obtained to share this patent's genelic sequencing data (e.g, a VCF flie) on restricted access databases.

I I conflim that consent has been obtained to share this patien'ts medical and family history on restricted access databases.

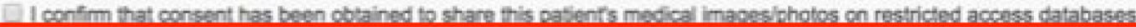

7 This patient is matchable through the MatchmakerExchange and you may receive occasional match notifications (unless you set the visibility to Private).

Update consentis

Figure 12.

PhenomeCentral users can enable matching over the Matchmaker exchange by checking the corresponding consent box when creating or editing a patient record. 

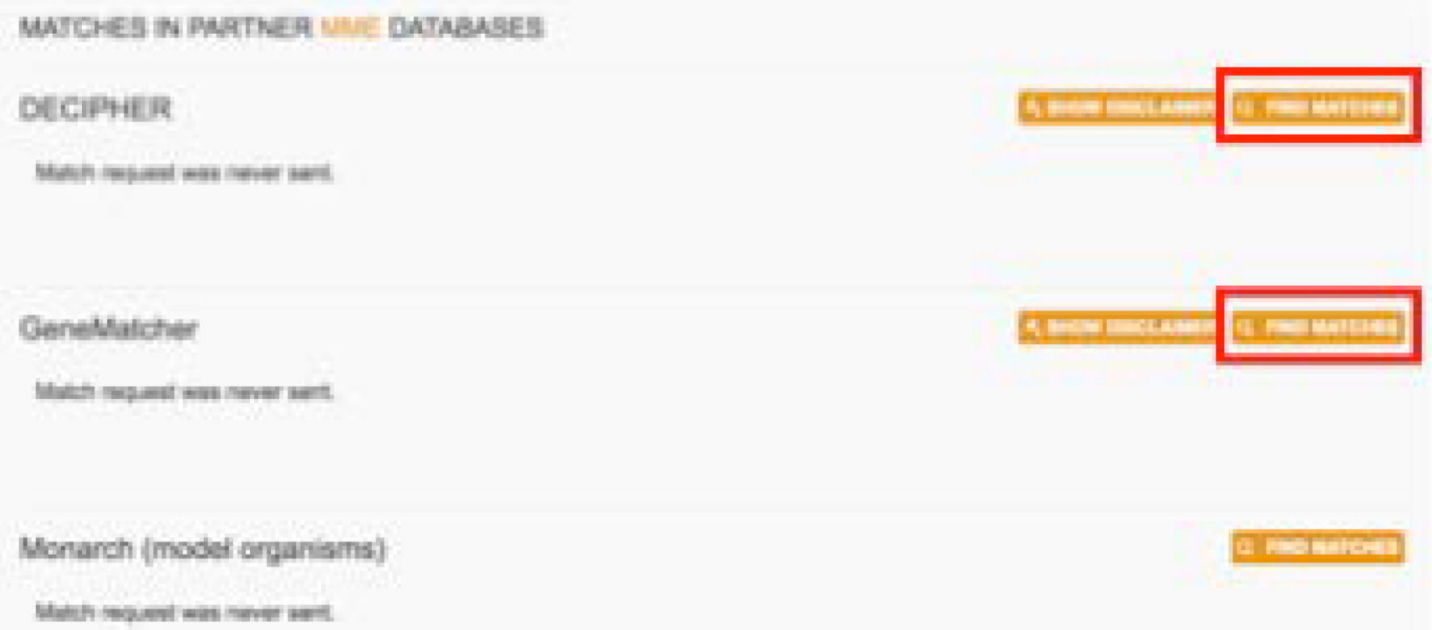

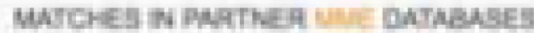

D. ciphitis

\section{Find Matches}

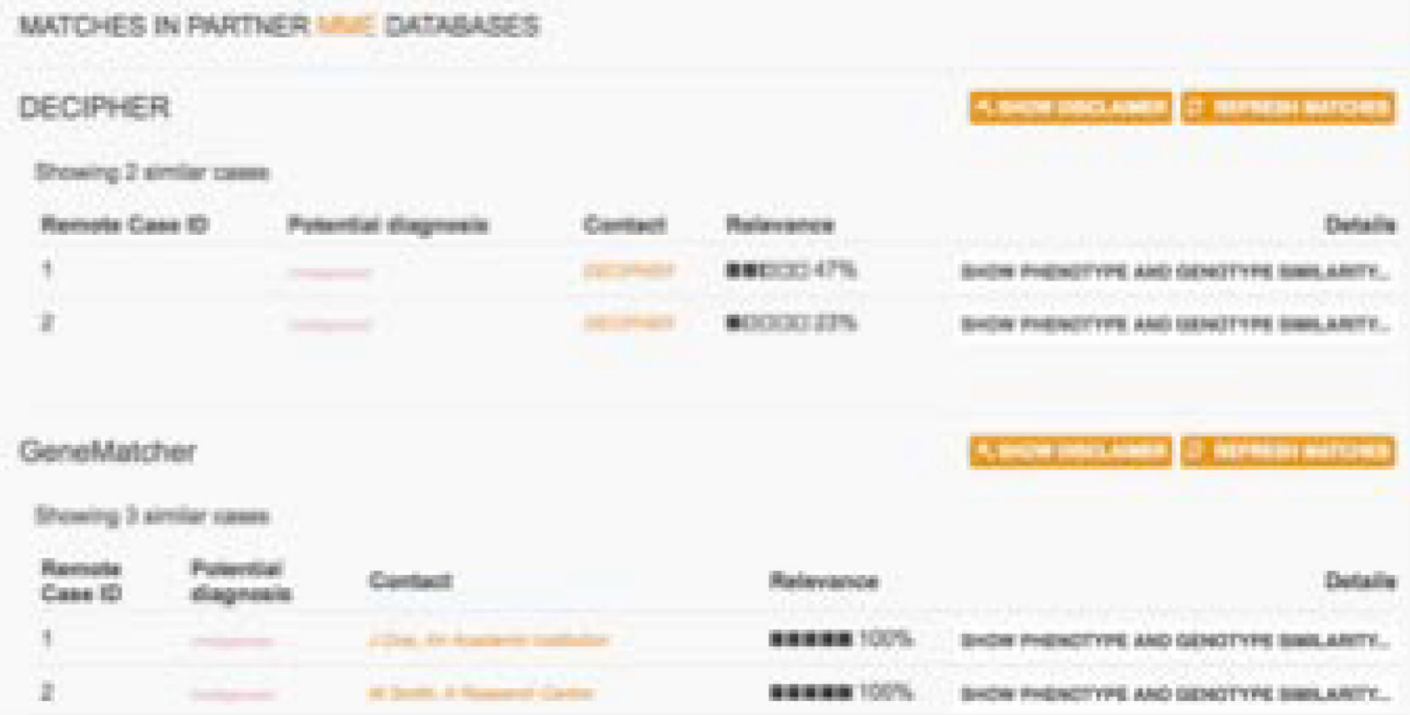

Figure 13.

PhenomeCentral users can find and view matches in other Matchmaker exchange databases by viewing a patient record, scrolling to the "Matches in partner Matchmaker exchange databases" section, and clicking "Find matches" next to the desired database (or "Refresh matches" to send a new request). Matches can then be reviewed and expanded to see a phenotype and genotype comparison. If the match is promising, the Contact link can be clicked to send an email to the other researcher or view a webpage with more information. 


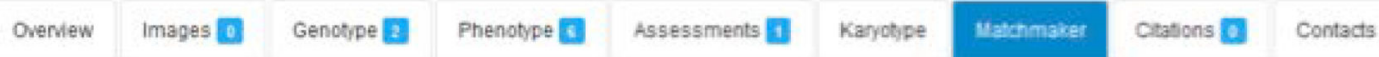

Through Matchmaker Exchange (MME) you can query 4 other patent databases for patents like this one, based on phenotipe and genotipe matches. The most similar results from each database will be listed below

Currently, we query the following database (with more to come)

- PhenomeCentral

- GeneMalchés

- MyGenear

- Broad-seqr

\section{Quen Hatchmaker Exchange}

Figure 14.

Matchmaker exchange tab in a patient record in the DECIPHER database. 


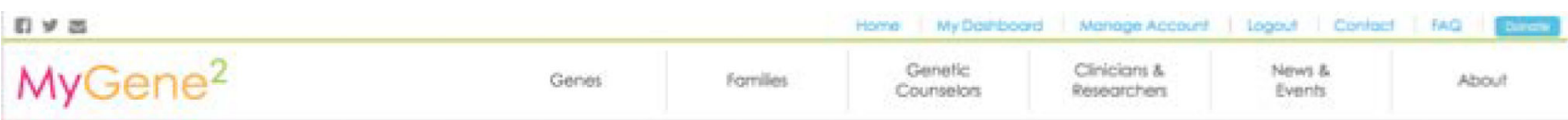

\section{MatchMaker Exchange Dashboard}

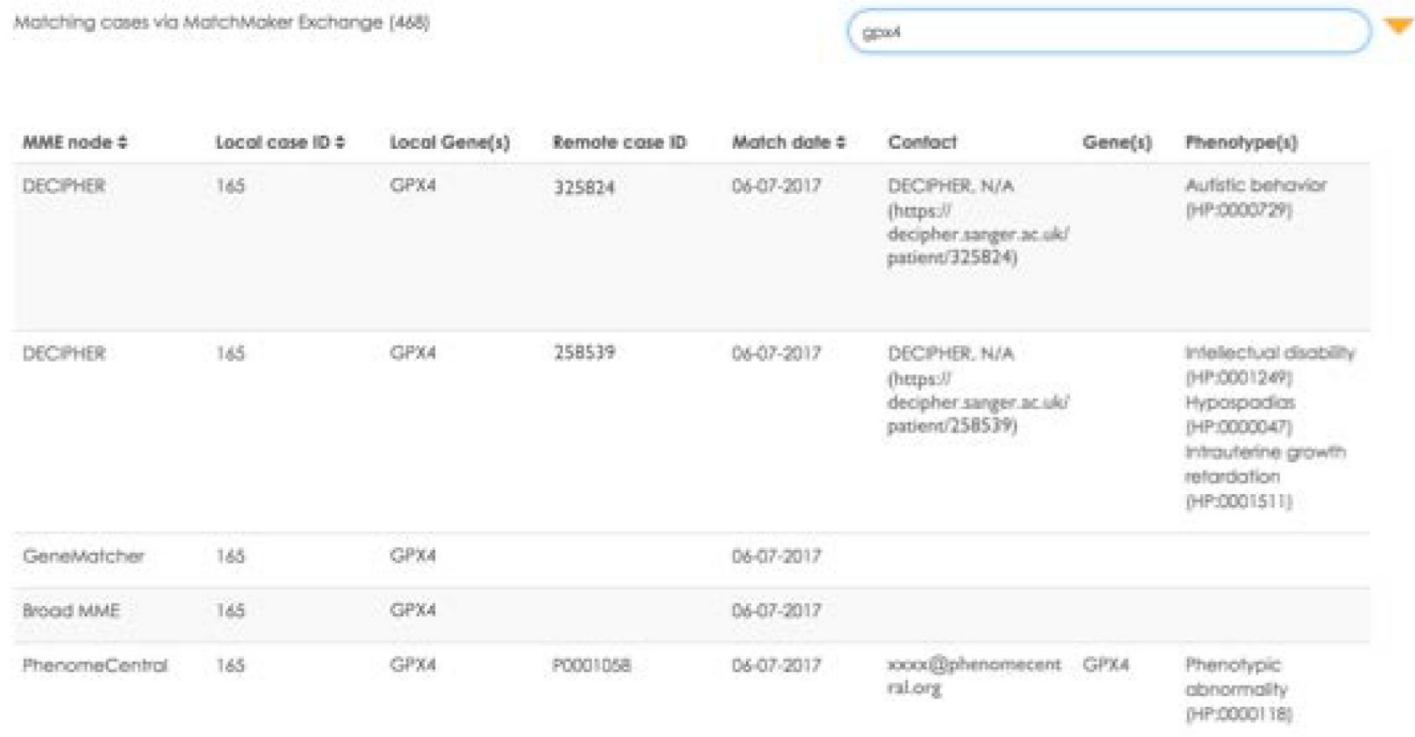

Figure 15.

Matchmaker Exchange Dashboard in the MyGene2 database. 


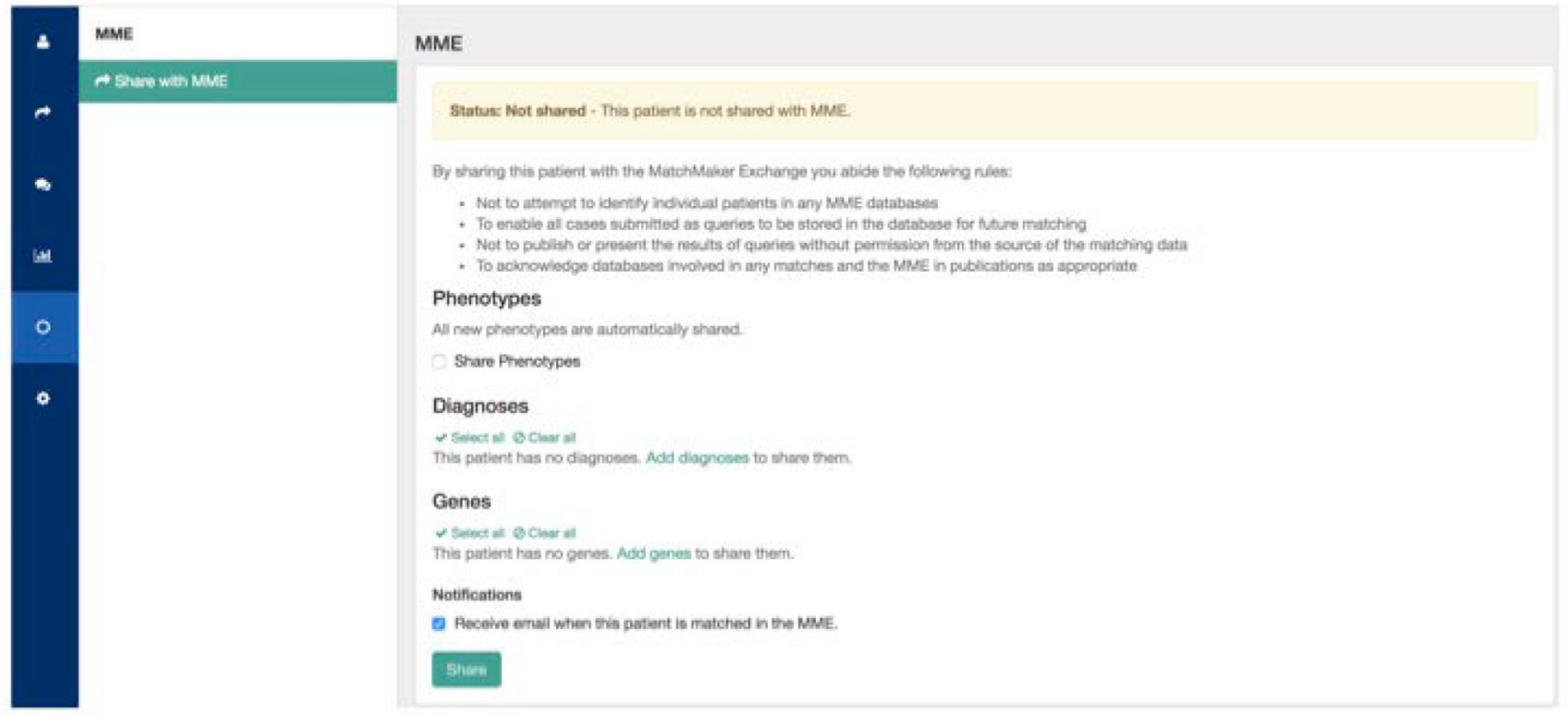

Figure 16.

Collaborators of the Broad CMG use the seqr web platform for analysis. matchbox is embedded within it, and is our bridge to the Matchmaker Exchange. Our collaborators first annotate phenotypes and candidate genotypes [1], and then select genes and phenotypes to submit and search with [2]. Then seqr, with the help of matchbox, finds similar patients globally and summarizes the information [3]. 


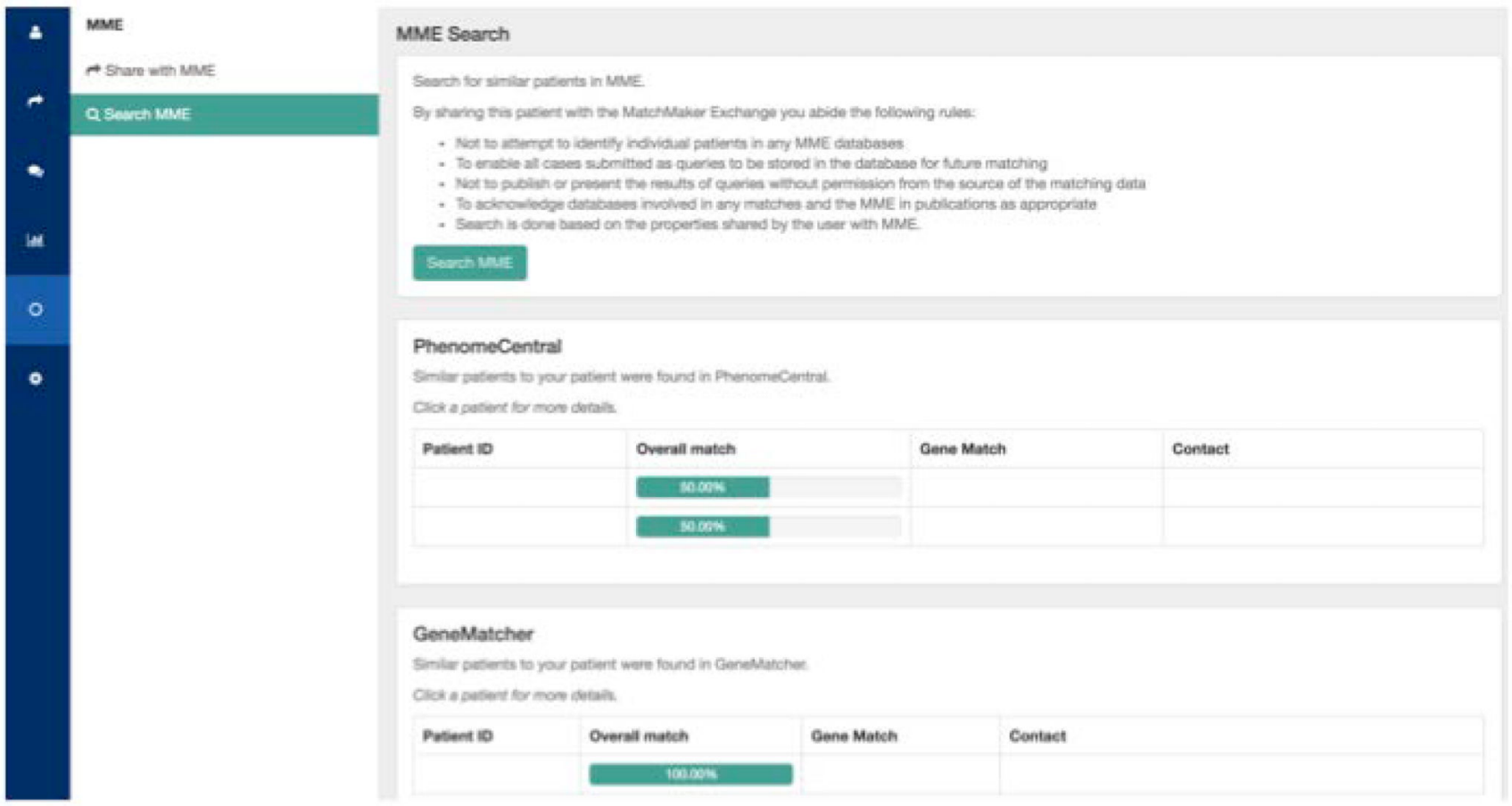

Figure 17.

How to send data from Australian Genomics Health Alliance Patient Archive to other Matchmaker exchange databases. 


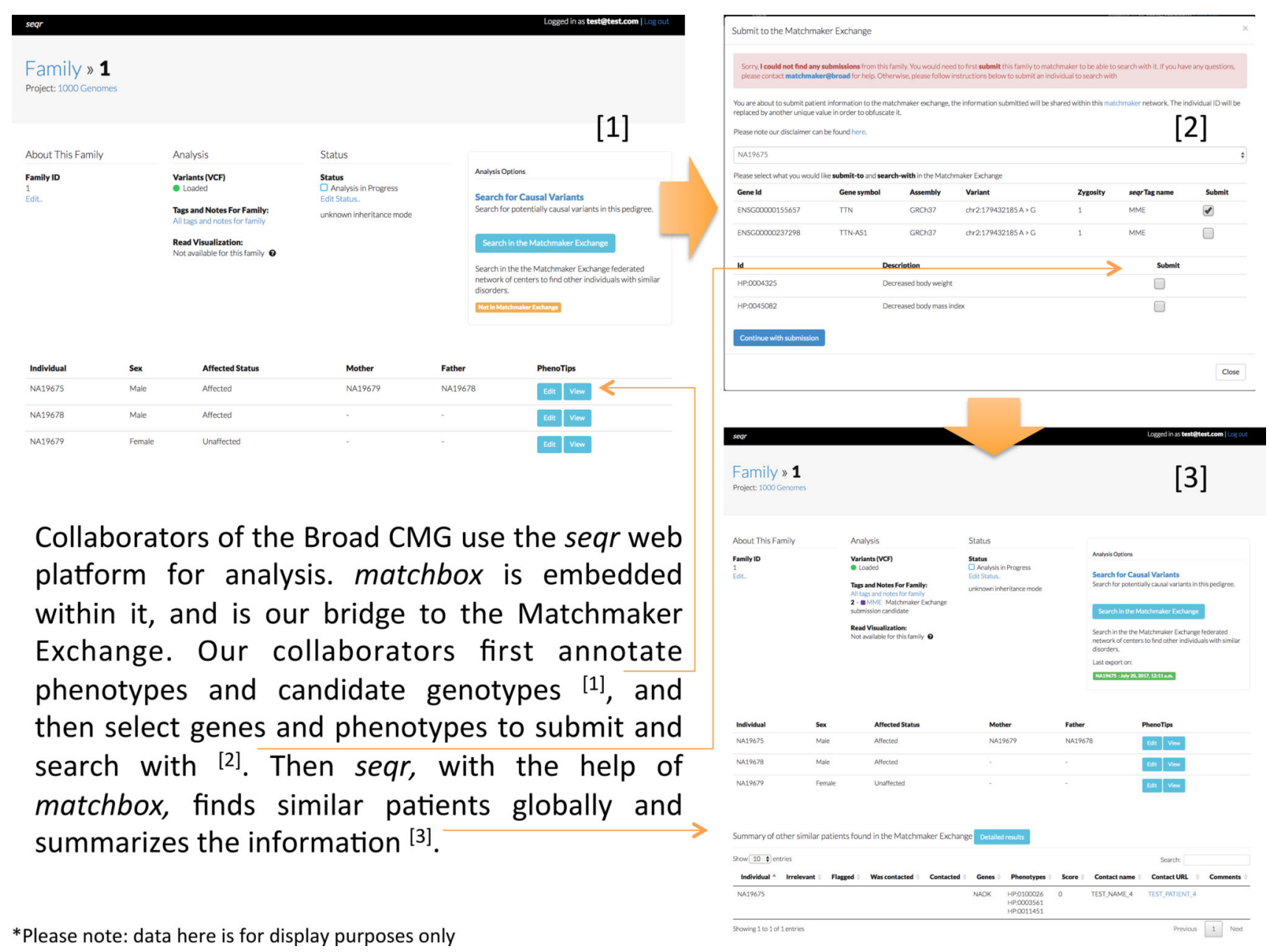

Figure 18.

Display of Matchmaker exchange matches in the Australian Genomics Health Alliance

Patient Archive. 